\section{Idiopathic tumoral calcinosis in children: Case report}

\author{
Dendane Mohamed Anouar ${ }^{1}$, Sadqi Rihab² and Alami Hassani \\ Zakarya $^{2 *}$
}

${ }^{1}$ Professor of Higher Education, Musculoskeletal Department, Faculty of Medicine and Pharmacy, Mohammed V University, Rabat, Morocco

${ }^{2}$ Resident Doctor, Musculoskeletal Department, Faculty of Medicine and Pharmacy, Mohammed V University, Rabat, Morocco

\section{Summary}

Tumoral calcinosis is a rare, benign entity characterized by the deposition of calcium in periarticular soft tissues. We report the original case of an idiopathic tumoral calcinosis of the elbow in a 6-year-old girl successfully treated by drainage with no signs of recurrence after a 3-year follow-up. We discuss the particularities of this joint location and our therapeutic management.

\section{More Information}

*Address for Correspondence:

Zakarya Alami Hassani, MD, Musculoskeletal Department, Faculty of Medicine and Pharmacy, Mohammed V University, Rabat, Morocco, Email: zakarya.alami@gmail.com

Submitted: October 25, 2021

Approved: November 22, 2021

Published: November 24, 2021

How to cite this article: Anouar DM, Rihab S, Zakarya $\mathrm{AH}$. Idiopathic tumoral calcinosis in children: Case report. Arch Surg Clin Res. 2021; 5: 023-025.

DOI: 10.29328/journal.ascr.1001061

ORCiD: orcid.org/0000-0003-1822-9666

Copyright: @ 2021 Anouar DM, et al. This is an open access article distributed under the Creative Commons Attribution License, which permits unrestricted use, distribution, and reproduction in any medium, provided the original work is properly cited.

Keywords: Tumor; Idiopathic calcinosis; Elbow; Drainage; Child

\section{Introduction}

Tumoral calcinosis or Teutschlaender disease is a relatively rare pseudotumor of unknown origin, characterized by the accumulation of calcium salts in periarticular soft tissues despite normal plasma levels of calcium and parathyroid hormone [1].

Classically, we distinguish the hyperphosphatemic form and the normophosphatemic form. The hyperphosphatemic form is usually familial, its autosomal recessive transmission is linked to mutations in FGF23, GALNT3 and SAMD3 genes, it is usually multilocular. The normophosphatemic form often occurs sporadically in adolescents and young black adults. It is usually mono-articular $[1,2]$.

We report the original observation of a tumoral calcinosis of the elbow, with no metabolic abnormalities in a 6-yearold patient. The disease is known to occur very rarely during the first decade. It was successfully treated by draining the content of the mass.

\section{Observation}

A 6-year-old girl, of North African origins and with no significant pathological history, presented with a swelling of the right elbow that had lasted for a year. Initially small and painless, the mass gradually increased in volume and became painful. The elbow extension was also restricted.

Physical examination revealed a very tense and painful swelling of the posterior side of the elbow, with no

\section{Check for updates}

OPEN ACCESS inflammatory signs, hard to palpation, ill-defined and adherent to deep planes, measuring $5 \times 5 \mathrm{~cm}$ (Figure 1).

This mass didn't allow any active or passive mobilization of the elbow, especially in extension. The rest of the somatic examination found no similar lesions in the other joints.

In addition, the parents did not report similar cases in the family and denied any previous osteo-articular trauma, immobilization or massage treatment.

Plain radiographs revealed the presence of a calcified pattern in the soft tissues located opposite to the posterior surface of the distal humerus (Figure 2a,b). Ultrasonographic study revealed a multiloculated and heterogeneous mass containing calcifications.

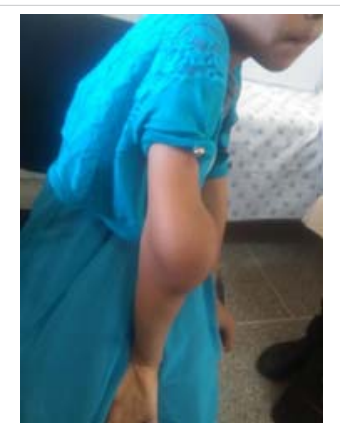

Figure 1: Clinical aspect of a tense mass of the posterior face of the right elbow. 
CT scan with 3D reconstruction eliminated any involvement of osteo articular skeleton and confirmed the presence of a budding mass with cauliflower appearance of $5 \mathrm{~cm} * 6 \mathrm{~cm}$, of mineral density, well limited and containing hypodense chambers (Figure 3).

Furthermore, metabolic tests (phosphorus, calcium, alkaline phosphatase and parathyroid hormone) were normal. The diagnosis of idiopathic tumoral calcinosis was heavily suggested.

We performed a drainage of the mass by a posterior approach of the elbow. Approximately $200 \mathrm{cc}$ of milky liquid was evacuated and the inner wall of the residual cavity was then curetted and padded (Figure 4).

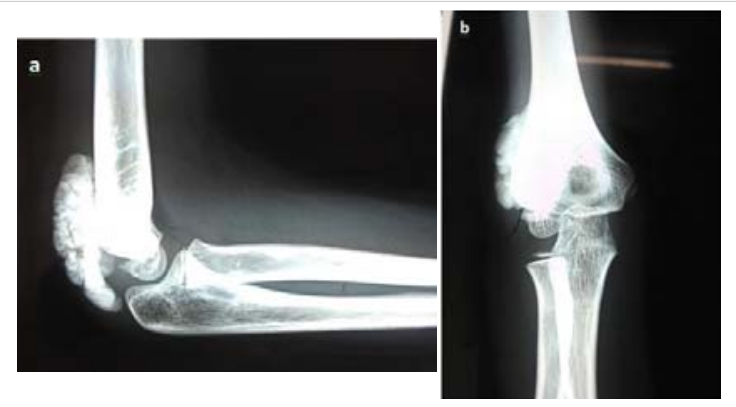

Figure 2: Calcified periarticular opacity of the soft tissues located opposite to the posterior surface of the humeral pallet: Lateral view (a) and Anteroposterior view (b).

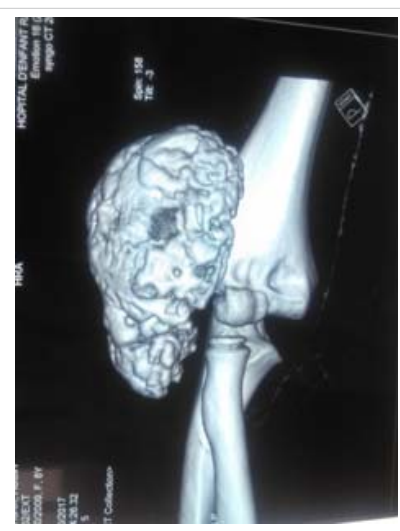

Figure 3: CT scan with 3D reconstruction in sagittal section showing an extra articular budding mass enclosing hypodense chamber.

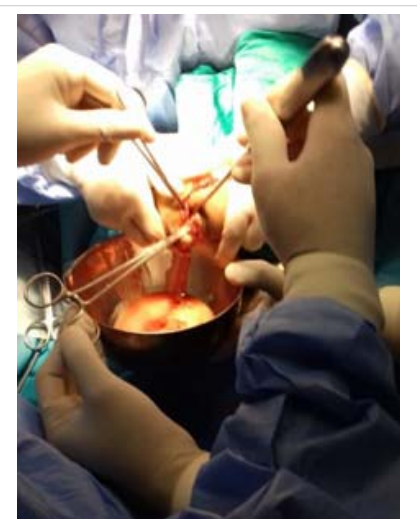

Figure 4: Drainage of the milky content of calcinosis.

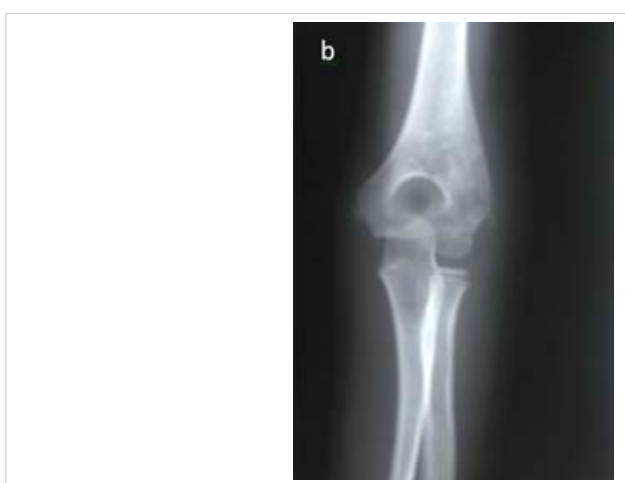

Figure 5: Radiological appearance after three years follow-up: Lateral view (a) Anteroposterior view (b).

Clinical outcome was good and pathological study showed the presence of multiple calcified, fibrinoid foci surrounded by a calcium deposit and a foreign-body giant cell reaction concluding to tumoral calcinosis.

After a 3-year follow-up, the patient has a normal elbow with no signs of clinical or radiological recurrence (Figure $5 a, b)$.

\section{Discussion}

Idiopathic tumoral calcinosis is characterized by the presence of one or more periarticular calcified masses, variable in size, with no phospho-calcium metabolism disorder, nor any cutaneous or visceral calcification $[3,4]$.

This entity is called primary normophosphatemic tumoral calcinosis in the classification of Pakasa, et al. [5] and belongs to ectopic bone calcifications in the Whyte classification [6].

Literature review reveals many theories to explain its pathogenesis, ranging from local tissue damage, hypothermia, to extravasation of calcium solution in the surrounding tissue. Our patient had no history of trauma nor previous treatments [7].

Our case matches these descriptions because no family history was found and serum phosphate levels were normal.

This observation is a rare expression of the disease since very few similar cases have been reported in the literature [3,8-11].

This normophosphatemic form of tumoral calcinosis usually occurs sporadically but a history of trauma or repetitive strain injuries are found in nearly half the cases $[1,2,8]$. In our patient, no trauma has been mentioned.

Tumoral calcinosis occurs very rarely during the first decade. Our patient would be the youngest in the literature with a localization in the limbs. Ashraf, et al. and Garrett, et al. reported 2 cases of idiopathic tumoral calcinosis among infants aged 5 and 34 months, respectively with cervical involvement in one and trunk involvement in the other $[10,11]$. 
In order of frequency, the elbow is the $3^{\text {rd }}$ site of tumoral calcinosis after the hip and shoulder $[9,12]$. In contrast to these two locations which remain asymptomatic for a long time, the elbow involvement is quickly responsible for a painful functional inconvenience probably due to the superficial nature of the joint and the impact on the articular motion, especially the extension. The clinical features in our patient illustrate this description.

The painful and hard character of the mass in our patient allowed to consider many diagnosis as soft tissue abscessation and heterotopic ossification. Abscessation of the calcinosis was also suspected without ruling out metastatic and dystrophic calcifications.

Plain radiography typically shows periarticular calcification as a juxtaposition of small, rounded, homogeneous and well limited densities, separated by radio-transparent septa. The cluster or honeycomb appearance is strongly suggestive of the diagnosis [13].

More recently, Di Serafino, et al. have described the chicken wire appearance as pathognomonic of tumoral calcinosis, which helps to distinguish it from other causes of soft tissue calcification [3].

CT scan and MRI allow a better characterization of the lesion and to clarify the relationship with musculoaponeurotic and bone structures.

Any pseudotumoral calcinosis that becomes symptomatic by its volume and/or location requires complete excision.

Typically, surgery is the essential treatment. It consists of a block resection of the tumor without tampering with the peritumoral capsule. This surgery should not leave any sequelae because of the strictly extra-articular location of the lesions $[11,12,14]$.

Our therapeutic approach was dictated by the painful and tense character of the mass that evoked a possible abscessation of the calcinosis. The risk of peroperative capsule effraction was taken into consideration in the decision-making.

We proceeded to drain the entire content of the lesion. The choice to drain rather than resect was dictated by the tense and liquid nature of the lesion, as well as the fear of an accidental effraction during resection.

We therefore decided to evacuate all tumor content and then resect the tumor capsule. The capsule's resection was difficult because of its retraction and adhesion to the surrounding tissues. The decision was then to curette massively the capsule's walls and to do a capitonnage of the remaining cavity. Long-term follow-up proved us right.

This approach has been little performed in the literature and seems to be reserved for small and / or asymptomatic calcinosis $[2,15]$.

There are also reports of medical therapy after resection. Probenecid, colchicine, magnesium or aluminum antacids were all reported to be effective in some cases of idiopathic tumoral calcinosis. Their aim is to prevent recurrence. However, the risks of such treatments overweight their benefits. Therefore, medical therapy is not recommended in children [16].

In adults, calcinosis usually occurs in the context of many comorbidities, thus the recurrence is frequent. That is not the case of idiopathic tumoral calcinosis in children. Few reports of recurrence have been reported, it is often linked to incomplete or late resection.

\section{Conclusion}

Idiopathic tumoral calcinosis is a rare condition in children. Considering the idiopathic nature of the disease, treatment is mostly surgical. The absence of recurrence in our patient is probably explained by the idiopathic nature of the calcinosis and the absence of metabolic disorder.

All authors contributed to the writing of this manuscript, all read and approved the final version.

\section{Ethical approval}

The patient and her parents written approval was obtained for publication of this case.

\section{References}

1. Tchermin D, Aubert S, Lesage A, Spac-Defasque E, DegrugillierChopinet C, et al. Soft tissue tumors. In: Cotten A, editor. Musculoskeletal Imaging: General Pathologies. 2d edition. Paris: Elsevier Masson. 2013; 529-579.

2. McCarthy EF. Pseudotumors and reactive lesions. Surg Pathol. 2012; 5: 257-286.

PubMed: https://pubmed.ncbi.nlm.nih.gov/26837924/

3. Di Serafino M, Gioioso M, Severino R, Lisanti F, Rocca R, et al. The idiopathic localized tumoral calcinosis: The chicken wire radiographic pattern. Radiol Case Rep. 2017; 12: 560-563.

PubMed: https://www.ncbi.nlm.nih.gov/pmc/articles/PMC5551916/

4. Fathi L, Sakr M. Review of tumoral calcinlosis: A rare clinicpathological entity. World J Clin Cases. 2014; 2: 409-414.

PubMed: https://www.ncbi.nlm.nih.gov/pmc/articles/PMC4163761/

5. Pakasa NM, Kalengayi RM. Tumoral calcinosis: a clinico pathological study of 111 cases with emphasis on the earliest changes. Histopathology. 1997; 31:18-24.

PubMed: https://pubmed.ncbi.nlm.nih.gov/9253620/

6. M. P. Sclerosing bone disorders. In: Rosen CJ, editor. Primer on the metabolic bone diseases and disorders of mineral metabolism. 7th edition. Washington: DC American Society of bone and mineral metabolism. 2008. 412-23.

7. Dhar D, Varghese TP. Idiopathic Soft Tissue Calcification in an Extremity: A Case Report. Oman Med J. 2013. 2: 131-132. PubMed: https://pubmed.ncbi.nlm.nih.gov/23599884/

8. Harouna $A D$, Atarraf $K$, Afifi MA. Primary pseudotumoral calcinosis in 
children Pan Afr Med J. 2017; 28: 239.

PubMed: https://pubmed.ncbi.nlm.nih.gov/29881484/

9. En-Nafaa L, Africha $T$, Boussouga $M$, Semlali $S$, Chaouir $S$, et al. Tumoral calcinosis: A case report. Arch Ped. 2010; 17: 1165-1168.

10. Ashraf A, Diehn FE, Luetmer PH, Lane JL, Fritchie K, et al. Infantile tumoral calcinosis of the cervical spine presenting as torticollis. Clin Imaging. 2016; 40: 161-163.

PubMed: https://pubmed.ncbi.nlm.nih.gov/26520701/

11. Booth GS, Vithana RE, DeMello DE, Mandell GA. Recurrent idiopathic tumoral calcinosis in a child post operatively. Radiol Case Rep. 2012; 7: 735.

PubMed: https://pubmed.ncbi.nlm.nih.gov/27330594/

12. Goldblum JR, Folpe AL, Weiss SW. Miscellaneous Benign Soft Tissue Tumors and Pseudotumors. In: Enzinger and Weiss's, editors. Soft tissue tumors. Sixth edition. Philadelphia: Elsevier. 2014; 947-968.

13. Diniz RL, Javier RM, Durckel J, Dietemann JL. What is it? Pseudotumoral calcinosis. J Radiol. 1999; 80: 597-599. PubMed: https://pubmed.ncbi.nlm.nih.gov/10417896/

14. Möckel G, Buttgereit F, Labs K, Perka C. Tumoral calcinosis revisited: pathophysiology and treatment. Rheumato Int. 2005; 25: 55-59. PubMed: https://pubmed.ncbi.nlm.nih.gov/13680142/

15. Johnson AR Jr, Mooshol DP, Thakar V, Williams M. Surgical Management of Idiopathic Ulcerative Calcinosis Cutis in the Lower Extremity: A Case Report. J Foot Ankle Sur. 2020; 59: 603-607. PubMed: https://pubmed.ncbi.nlm.nih.gov/31732275/

16. Venkatesh Gupta SK, Balaga RR, Banik SK. Idiopathic Calcinosis Cutis over Elbow in a 12-Year Old Child. Case Rep Orthop. 2013; 241891. PubMed: https://www.ncbi.nlm.nih.gov/pmc/articles/PMC3835332/ 